\title{
Skepinone-L, a Novel Potent and Highly Selective Inhibitor of p38 MAP Kinase, Effectively Impairs Platelet Activation and Thrombus Formation
}

\author{
Oliver Borst ${ }^{a, b}, \mathrm{e} \quad$ Britta Walker ${ }^{\mathrm{a}, \mathrm{e}}$ Patrick Münzer ${ }^{\mathrm{a}, \mathrm{e}} \quad$ Antonella Russo ${ }^{\mathrm{a}, \mathrm{d}} \quad$ Evi Schmid $^{\mathrm{a}}$ \\ Caterina Faggio ${ }^{d} \quad$ Boris Bigalke ${ }^{b} \quad$ Stefan Laufer ${ }^{c}$ Meinrad Gawaz ${ }^{b} \quad$ Florian Lang $^{a}$ \\ ${ }^{a}$ Department of Physiology, University of Tübingen, Germany; ${ }^{b}$ Department of Cardiology and \\ Cardiovascular Medicine, University of Tübingen, Germany; 'Department of Pharmacy, University of \\ Tübingen, Germany; ${ }^{d}$ Department of Biological and Environmental Sciences, University of Messina, Italy; \\ econtributed equally and thus share first authorship
}

\section{Key Words}

Aggregation - p38 MAPK - Secretion - Skepinone-L - Thrombus formation - Thromboxane synthesis

\begin{abstract}
Background/Aims: Platelets are critically important for primary haemostasis and the major players in thrombotic vascular occlusion. Platelets are activated by agonists, such as thrombin and collagen-related peptide as well as second-wave mediators including thromboxane $A_{2}$ via different intracellular signaling pathways resulting in degranulation, aggregation and thrombus formation. Platelet activation is paralleled by phosphorylation and activation of p38 MAPK. The limited specificity of hitherto known p38 MAPK inhibitors precluded safe conclusions on the precise role of 338 MAPK in the regulation of platelet function. The present study examined the impact of Skepinone-L, a novel and highly selective inhibitor of p38 mitogen-activated protein kinase (p38 MAPK), on platelet activation and thrombus formation. Methods: Experiments were performed in freshly isolated human platelets. Protein phosphorylation was quantified by Western blotting, thromboxane $\mathrm{B}_{2}$ synthesis by enzyme immunoassay, ATP release by ChronoLume luciferin assay, cytosolic $\mathrm{Ca}^{2+}$ concentration by Fura-2 fluorescence-measurements, platelet aggregation by a light transmissions measurement and in vitro thrombus formation by a flow chamber. Results: Skepinone- $L$ $(1 \mu \mathrm{M})$ virtually abrogated the phosphorylation of platelet p38 MAPK substrate Hsp27 following stimulation with CRP $(1 \mu \mathrm{g} / \mathrm{ml})$, thrombin $(5 \mathrm{mU} / \mathrm{ml})$ or thromboxane $A_{2}$ analogue U-46619 (1 $\mu \mathrm{M})$. Furthermore, Skepinone-L significantly blunted activation-dependent platelet secretion and aggregation following threshold concentrations of CRP, thrombin and thromboxane $A_{2}$ analogue $U$-46619. Skepinone-L did not impair platelet $\mathrm{Ca}^{2+}$ signaling


but prevented agonist-induced thromboxane $A_{2}$ synthesis through abrogation of p38 MAPKdependent phosphorylation of platelet cytosolic phospholipase $A_{2}\left(C P L A_{2}\right)$. Skepinone- $L$ further markedly blunted thrombus formation under low (500-s) and high (1700-s) arterial shear rates. Conclusions: The present study discloses a powerful inhibiting effect of p38 MAPK-blocker Skepinone- $L$ on platelet activation and thrombus formation.

Copyright (C) 2013 S. Karger AG, Basel

\section{Introduction}

Platelets are key players in primary haemostasis following vascular injury as well as in acute thrombotic occlusion after rupture or erosion of atherosclerotic plaques resulting in myocardial infarction or ischemic stroke [1,2]. Platelets are activated by numerous agonists including collagen-related peptide and thrombin as well as the second wave mediators thromboxane $\mathrm{A}_{2}$ and ADP [3]. Platelet activation following adhesion to collagen results in degranulation, aggregation and thrombus formation [4].

Platelet activation is modified by several signaling pathways and kinases including p38 mitogen-activated protein kinase (MAPK), which is expressed in platelets [5] and activated by thrombin $[6,7]$, thromboxane $\left(\mathrm{TXA}_{2}\right)[8]$ or collagen $[8,9]$. The activation is paralleled by phosphorylation of the kinase [10-16].

p38MAPKis a potentactivator of MAPK-activated protein kinase-2, which phosphorylates the small heat shock protein 27 (Hsp27). While in the resting state platelet Hsp27 is mainly unphosphorylated and located in the cytoplasm, after platelet stimulation Hsp27 is phosphorylated and translocated to the cytoskeleton [17]. Thus, Hsp27 phosphorylation upon platelet stimulation was measured as an indicator of p38 MAPK activity [8].

It has been speculated that p38 MAPK could act as an important signaling kinase in the regulation of platelet adhesion and spreading $[15,18]$, which requires p38 MAPK dependent actin cytoskeleton reorganization [19]. It has already been shown that platelet p38 MAPK is required for thrombin- and collagen-dependent phosphorylation of cytosolic phospholipase $A_{2}\left(\mathrm{CPLA}_{2}\right)[7,20]$ with subsequent release of thromboxane $A_{2}\left(\mathrm{TXA}_{2}\right)$ production $[5,21]$. But the impact of p38 MAPK on platelet aggregation following different platelet agonists still remains a matter of debate. Furthermore, the role of p38 MAPK in platelet secretion and thrombus formation under different shear rates remains largely unclear.

By using the inhibitors VX-702 and SB203580 platelet p38 MAPK was reported not to be required for platelet calcium influx following stimulation with thrombin or thromboxane analogue U-46619 [21, 22], but appears to be essential for platelet aggregation induced by U-46619 [23] as well as low and medium concentrations of collagen [8, 22].

Knowledge on the functional significance of p38 MAPK in platelets is in large part dependent on pharmacological inhibition of the kinase by SB203580 and SB202190 [19] or VX-702 [21]. The majority of p38 MAPK inhibitors are only moderately potent in physiologically relevant whole blood studies [24] and require high dosing in vivo to achieve effective plasma concentrations [25]. Most p38 inhibitors including SB203580 and SB202190 are effective via their ATP-competitive binding mode and display poor selectivity because the ATP-binding site is highly conserved among a variety of proteins $[25,26]$. Recently, Skepinone-L, a highly selective inhibitor of p38 MAPK has been developed. Skepinone-L is, to our knowledge, the first ATP-competitive p38 MAPK inhibitor with excellent in vivo efficacy and selectivity $[25,27]$. At a concentration of $1 \mu \mathrm{M}$, Skepinone-L did not bind any of the tested kinases in two different selectivity screens except p38 MAPK [25]. Following that knowledge, p38 MAPK dependent pathways in platelet activation can be explored exactly.

The present study thus examined the effect of the novel p38 MAPK inhibitor Skepinone-L on platelet function, especially with focus on secretion, $\mathrm{Ca}^{2+}$ influx, thromboxane synthesis and aggregation following threshold and maximal concentrations of different platelet agonists speculated to be effective through platelet p38 MAPK signaling. Furthermore, the present study examined for the first time the impact of selective and potent inhibiton of $\mathrm{p} 38$ MAPK by Skepinone-L on thrombus formation under different arterial shear rates. 


\section{Materials and Methods}

\section{Chemicals}

Platelets were activated using collagen-related peptide (CRP, provided by R. Farndale, University of Cambridge, United Kingdom), thrombin (Roche) or the thromboxane $A_{2}$ analogue U-46619 (Enzo). Skepinone-L was generated by S. Laufer (University of Tübingen, Germany) as described previously [25].

\section{Preparation of human platelets}

Human platelets were isolated as described previously [28]. Blood from healthy volunteers was collected in ACD buffer and centrifuged at $200 \mathrm{~g}$ for 20 minutes. The obtained platelet-rich plasma was added to modified Tyrode-HEPES (N-2-hydroxyethyl-piperazone-N'2-ethanesulfonic acid) buffer (137 mM $\mathrm{NaCl}, 2.8 \mathrm{mM} \mathrm{KCL}, 12 \mathrm{mM} \mathrm{NaHCO}{ }_{3}, 5 \mathrm{mM}$ glucose, $0.4 \mathrm{mM} \mathrm{Na}_{2} \mathrm{HPO}_{4}, 10 \mathrm{mM}$ HEPES, 0.1\% bovine serum albumin, $\mathrm{pH}$ 6.5). After centrifugation at $900 \mathrm{~g}$ for 10 minutes and removal of the supernatant, the resulting platelet pellet was resuspended in Tyrode-HEPES buffer ( $\mathrm{pH} 7.4$, supplemented with $1 \mathrm{mM} \mathrm{CaCl}_{2}$ ).

\section{Western blot analysis}

To examine phosphorylation of MAPK p38 protein kinase effector Hsp27 as well as phosphorylation of $\mathrm{CPLA}_{2}$, isolated platelets were lysed in lysis buffer (50 mM Tris- $\mathrm{HCl}, \mathrm{pH} 7.4,150 \mathrm{mM} \mathrm{NaCl}, 1 \%$ Triton-X, $0.5 \% \mathrm{Na}_{2} \mathrm{HPO}_{4}, 0.4 \% \beta$-mercaptoethanol) containing protease inhibitor cocktail (Roche). Proteins (40 $\mu \mathrm{g}$ ) were solubilized in Laemmli sample buffer at $95^{\circ} \mathrm{C}$ for 5 minutes and resolved by $10 \%$ SDS-PAGE. For immunoblotting proteins were electro-transferred onto a nitrocellulose membrane and blocked with 10 $\%$ nonfat milk in TBS- $0.1 \%$ Tween 20 (TBST) at room temperature for 1 hour. Then, the membrane was incubated with affinity purified rabbit anti-pHsp27 (1:1000; Cell Signaling) or anti-phospho (Ser $\left.{ }^{505}\right)^{c_{2 L A}}$ (1:1000, Cell Signaling) and actin antibody (1:1000, Cell Signaling) as loading control at $4^{\circ} \mathrm{C}$ overnight. After washing 3 times with TBST (10 minutes each) the blots were incubated with horseradish peroxidase conjugated secondary anti-rabbit antibody (1:3000; Cell Signaling) for 1 hour at room temperature. After washing antibody binding was detected with the ECL detection reagent (Amersham). Antibody-binding was quantified densitometrically with Quantity One Software (Biorad, München, Germany).

\section{Thromboxane synthesis}

Because thromboxane $\mathrm{A}_{2}\left(\mathrm{TXA}_{2}\right)$ is very unstable and rapidly hydrolyzed into stable metabolite thromboxane $\mathrm{B}_{2}\left(\mathrm{TXB}_{2}\right)$, we measured the latter instead of TXA $\mathrm{T}_{2}$. After the challenge of platelet agonists for 5 minutes in the presence or absence of Skepinone-L, EDTA ( $2 \mathrm{mmol} / \mathrm{L})$ and indomethacin $(50 \mu \mathrm{mol} / \mathrm{L})$ were added to stop reactions as described previously [29]. The platelet suspensions were centrifuged for 3 minutes at $13,000 \mathrm{~g}$, and $\mathrm{TXB}_{2}$ in the supernatants were assayed using an enzyme immunoassay (EIA) kit according to the manufacturer's ELISA instructions (Cayman Chemical).

\section{ATP release}

ATP release was determined to study degranulation of platelet dense granules. To this end, isolated human platelets were pretreated either with $1 \mu \mathrm{M}$ Skepinone-L or DMSO as solvent control for 15 minutes at $37^{\circ} \mathrm{C}$ and activated by different agonist concentrations. For determination of ATP release, the isolated platelets were adjusted to a concentration of $250 \times 10^{6}$ platelets per $\mu \mathrm{l}$. After calibration of one sample with ATP standard (ChronoLog, Havertown, USA), the ATP concentration was determined utilizing the ChronoLume luciferin assay (ChronoLog) on a luminoaggregometer (Modell 700, ChronoLog) according to the manufacturer's protocol.

\section{Platelet aggregometry}

Aggregation of isolated human platelets was studied at a concentration of $250 \times 10^{6}$ platelets per $\mu \mathrm{l}$ in Tyrode buffer pH 7.4 and was estimated from light transmission determined with a luminoaggregometer model 700 (ChronoLog). After adjusting the measurement according to the manufacturer's protocol platelets were activated for 10 minutes, $37^{\circ} \mathrm{C}$ and a stirr speed of $1000 \mathrm{rpm}$ with the indicated concentrations of agonists. Analysis was performed with the aggrolink8 software (ChronoLog). 


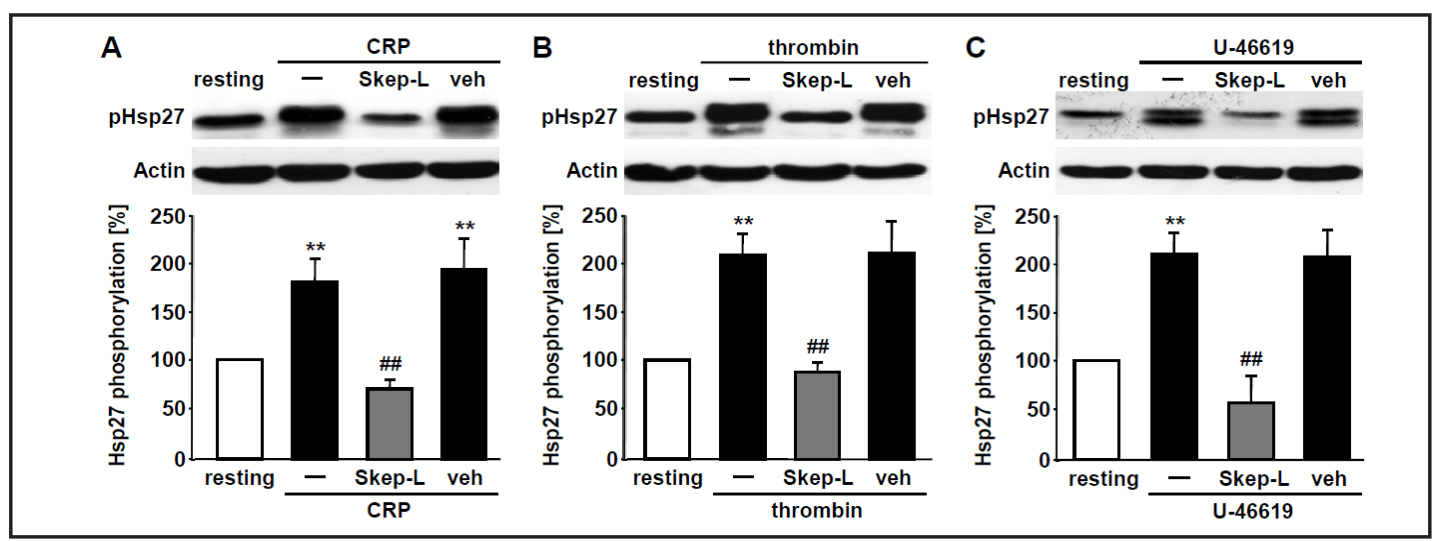

Fig. 1. Skepinone-L abrogates activation-dependent Hsp27 phosphorylation in platelets. Representative Western blots and arithmetic means \pm SEM $(n=4-6)$ demonstrating the expression of phosphorylated Hsp27 and of the respective actin protein abundance in isolated human platelets prior to (resting) or following stimulation with either CRP $(1 \mu \mathrm{g} / \mathrm{ml}, \mathrm{A})$, thrombin $(5 \mathrm{mU} / \mathrm{ml}, \mathrm{B})$ or thromboxane $\mathrm{A}_{2}$ analogue $\mathrm{U}-46619$ $(1 \mu \mathrm{M}, \mathrm{C})$ in the presence of Skepinone-L $(1 \mu \mathrm{M})$ or vehicle (DMSO). ${ }^{* *}(\mathrm{p}<0.01)$ indicates significant difference from value prior to activation, ${ }^{\# \#}(\mathrm{p}<0.01)$ indicates significant difference between pretreatment with Skepinone-L or vehicle (DMSO).

\section{Calcium measurements}

Washed platelets were suspended in Tyrode buffer without calcium and loaded with $5 \mu \mathrm{M}$ Fura-2 acetoxymethylester (Invitrogen) in the presence of $0.2 \mu \mathrm{g} / \mathrm{ml}$ Pluronic F-127 (Biotium) at $37^{\circ} \mathrm{C}$ for 30 minutes. Loaded platelets, washed once and resuspended in Tyrode buffer containing 0.5 mM EGTA (Roth) or $1 \mathrm{mM} \mathrm{Ca}^{2+}$, were activated with indicated agonists. Calcium responses were measured under stirring with a spectrofluorimeter (LS 55, PerkinElmer), at alternate excitation wavelength of 340 and $380 \mathrm{~nm}\left(37^{\circ} \mathrm{C}\right)$. The 340/380 nm ratio values were converted into nanomolar concentrations of $\left[\mathrm{Ca}^{2+}\right]$ by lysis with Triton X-100 (Sigma-Aldrich) and a surplus of EGTA.

\section{In vitro thrombus formation}

Heparinized whole mouse blood was diluted 1:3 in modified Tyrode buffer ( $\mathrm{pH} 7.4$ ) and perfused through a transparent flow chamber (slit depth $50 \mu \mathrm{m}$ ) over a collagen-coated surface $(200 \mu \mathrm{g} / \mathrm{ml}) \mathrm{with}$ a wall shear rate of $500^{\text {ss }}$ (low shear rate) or $1700^{-s}$ (high shear rate) for 5 minutes. After perfusion the chamber was rinsed for 5 minutes by perfusion with Tyrode buffer ( $\mathrm{pH} 7.4$ ) and pictures were taken from 5 to 6 different microscopic areas ( $20 \mathrm{x}$, Carl Zeiss). Analysis was done with AxioVision (Carl Zeiss) and the mean percentage value of the covered area was determined.

\section{Statistical analysis}

Data are provided as means \pm SD or SEM, $n$ represents the number of experiments. All data were tested for significance using paired or unpaired Student t-test and one-way ANOVA with Dunnets post-hoc test. Results with $\mathrm{p}<0.05$ or $\mathrm{p}<0.01$ were considered statistically significant.

\section{Results}

Skepinone-L decreased p38 MAPK-dependent phosphorylation of Hsp27 upon platelet stimulation.

In a first series of experiments Western blot analysis was employed to determine the cellular potency of Skepinone-L. Platelets were treated with different agonists potentially activating platelet p38 MAPK. The level of stimulation-dependent phosphorylation of heat shock protein 27 (Hsp27) through the p38 MAPK pathway was determined as a marker of platelet p38 MAPK activity.

As illustrated in Fig. 1, activation of platelets with CRP $(1 \mu \mathrm{g} / \mathrm{ml}, \mathrm{A})$, thrombin ( $5 \mathrm{mU} / \mathrm{ml}, \mathrm{B})$ or the thromboxane $\mathrm{A}_{2}$ analogue $\mathrm{U}-46619(1 \mu \mathrm{M}, \mathrm{C})$ was followed by a marked 


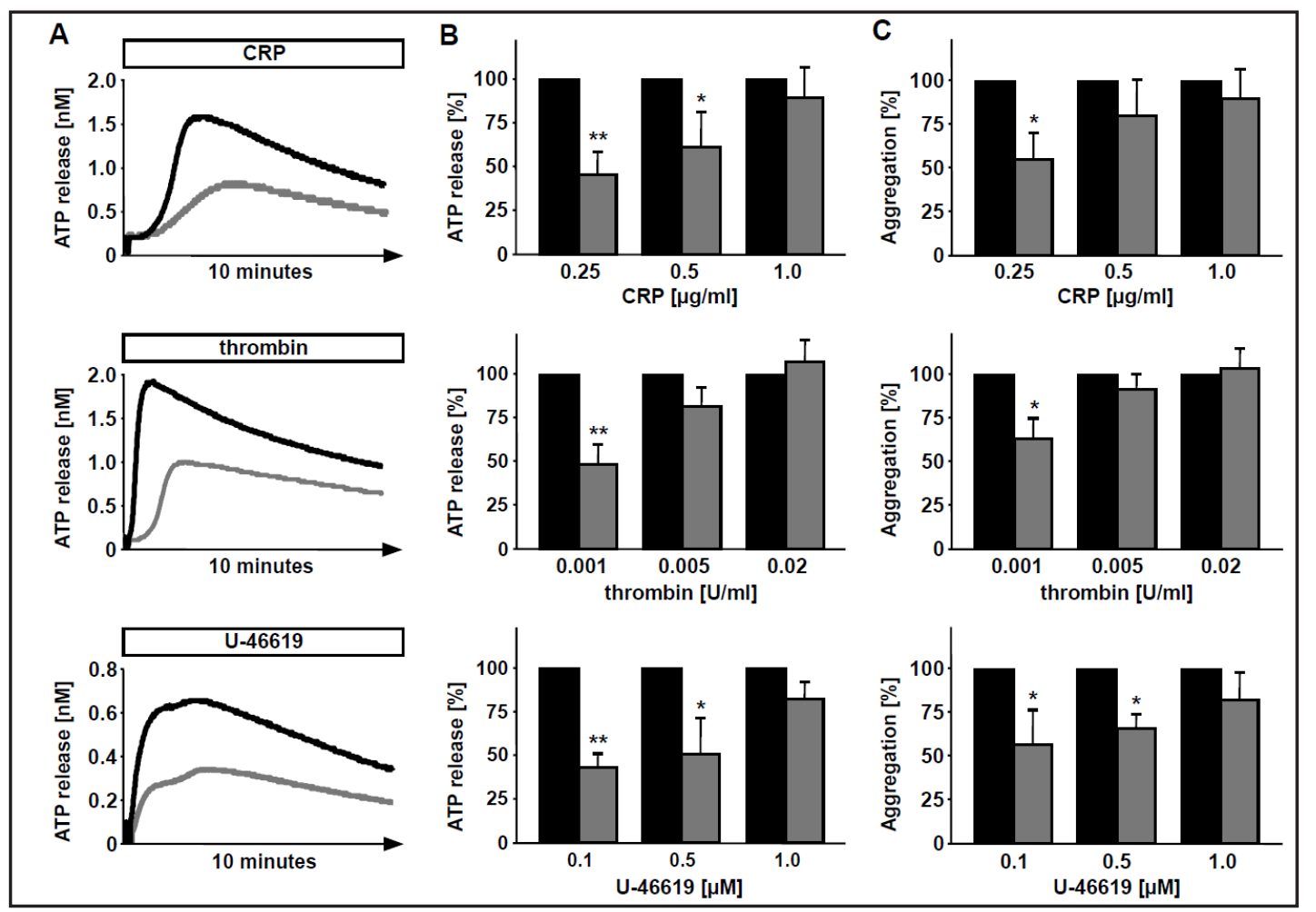

Fig. 2. Skepinone-L significantly affects activation-dependent platelet secretion and aggregation. A. Representative tracings illustrating the increase of ATP concentration in platelet supernatant following stimulation with either $0.25 \mu \mathrm{g} / \mathrm{ml}$ collagen-related peptide (CRP), $1 \mathrm{mU} / \mathrm{ml}$ thrombin or $0.1 \mu \mathrm{M}$ thromboxane $A_{2}$ analogue U-46619 in the absence (black tracings) and presence (grey tracings) of Skepinone-L $(1 \mu \mathrm{M})$. B. Arithmetic means \pm SEM $(n=6)$ of ATP concentration in platelet supernatant following stimulation of platelets with collagen-related peptide (CRP, 0.25-1.0 $\mu \mathrm{g} / \mathrm{ml})$, thrombin (1-20 mU/ml) or U-46619 (0.1-1.0 $\mu \mathrm{M})$ in the absence (black bars) or presence (grey bars) of Skepinone-L $(1 \mu \mathrm{M}){ }^{*}(\mathrm{p}<0.05)$ and ${ }^{* *}(\mathrm{p}<0.01)$ indicate significant difference between pretreatment with Skepinone-L or vehicle (DMSO). C. Arithmetic means \pm SEM $(n=6)$ of light transmission aggregometry following stimulation of platelets with collagenrelated peptide (CRP, $0.25-1.0 \mu \mathrm{g} / \mathrm{ml}$ ), thrombin $(1-20 \mathrm{mU} / \mathrm{ml})$ or the thromboxane $A_{2}$ analogue U-46619 $(0.1-1.0 \mu \mathrm{M})$ in the absence (black bars) and presence (grey bars) of Skepinone-L $(1 \mu \mathrm{M}){ }^{*}(\mathrm{p}<0.05)$ indicates significant difference between pretreatment with Skepinone-L or vehicle (DMSO).

increase of Hsp27 phosphorylation. The increase of phosphorylated Hsp27 was abrogated in the presence of $1 \mu \mathrm{M}$ Skepinone-L, but not in the presence of DMSO, used as vehicle (Fig. 1).

Further experiments explored the functional significance of Skepinone-L sensitive p38 MAP kinase activity.

Inhibition of platelet 38 MAPK activity by Skepinone-L abrogated stimulation-dependent platelet secretion and aggregation in response to threshold agonist concentrations.

To elucidate the impact of Skepinone-L on platelet secretion, ATP release (dense granules) was quantified prior to and following agonist activation with increasing concentrations of CRP $(0.25,0.5$ and $1 \mu \mathrm{g} / \mathrm{ml})$, thrombin $(1,5$ and $20 \mathrm{mU} / \mathrm{ml})$ and thromboxane $\mathrm{A}_{2}$ analogue $\mathrm{U}-46619(0.1,0.5$ and $1.0 \mu \mathrm{M})$ in the presence of Skepinone-L $(1 \mu \mathrm{M})$ or DMSO (vehicle). As illustrated in Fig. $2 \mathrm{~A}$ and B, treatment of platelets with thrombin, CRP or thromboxane $A_{2}$ analogue U-46619 was followed by a sharp increase of ATP release (luminescence analysis). Skepinone-L significantly blunted the ATP release following stimulation with low concentrations of either thrombin $(1 \mathrm{mU} / \mathrm{ml})$ or CRP $(0.25$ and $0.5 \mu \mathrm{g} / \mathrm{ml})$. Increasing concentrations of CRP and thrombin overcame the inhibitory effect of Skepinone-L, whereas Skepinone-L blocked 
Fig. 3. Agonist-induced $\mathrm{Ca}^{2+}$ influx in platelets in absence and presence of SkepinoneL. A. Representative tracings and arithmetic means \pm SEM $(n=4)$ of maximal $\Delta\left[\mathrm{Ca}^{2+}\right]$ of Fura-2-fluorescence reflecting cytosolic $\mathrm{Ca}^{2+}$ concentration $\left[\mathrm{Ca}^{2+}\right]_{\mathrm{i}}$ in platelets prior to and following stimulation with collagenrelated peptide (CRP $0.5 \mu \mathrm{g} / \mathrm{ml}$ ) in the absence (black curve and bar) and presence (grey curve and bar) of Skepinone-L (1 $\mu \mathrm{M})$. B. Representative tracings and arithmetic means \pm SEM $(n=4)$ of maximal $\Delta\left[\mathrm{Ca}^{2+}\right]_{\mathrm{i}}$ of Fura-2-fluorescence reflecting cytosolic $\mathrm{Ca}^{2+}$ concentration $\left[\mathrm{Ca}^{2+}\right]_{\mathrm{i}}$ in platelets prior to and following stimulation with thrombin $(5 \mathrm{mU} / \mathrm{ml})$ in the absence (black curve and bar) and presence (grey curve and bar) of Skepinone-L ( $1 \mu \mathrm{M})$. C. Representative tracings and arithmetic means \pm SEM $(n=4)$ of maximal $\Delta\left[\mathrm{Ca}^{2+}\right]_{i}$ of Fura-2-fluorescence reflecting cytosolic $\mathrm{Ca}^{2+}$ concentration $\left[\mathrm{Ca}^{2+}\right]_{\mathrm{i}}$ in platelets prior to and following stimulation with thromboxane $A_{2}$ analogue U-46619 (0.5 $\mu \mathrm{M}$ ) in the absence (black curve and bar) and presence (grey curve and bar) of Skepinone-L $(1 \mu \mathrm{M})$.
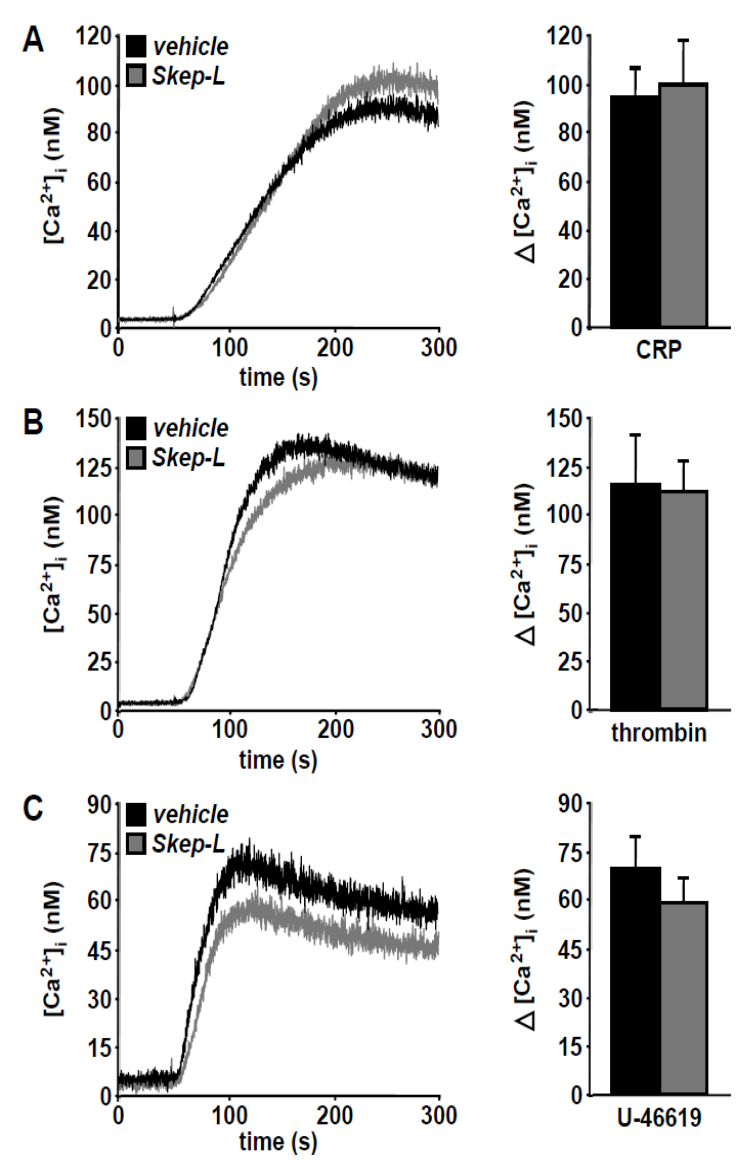

stimulation-dependent degranulation following submaximal concentrations of thromboxane analogue $A_{2} U-46619(0.1-0.5 \mu \mathrm{M})$.

In a next series of experiments, light transmission measurements of platelet aggregation were performed prior to and following activation with increasing concentrations of CRP $(0.25$, 0.5 and $1 \mu \mathrm{g} / \mathrm{ml})$, thrombin $(1,5$ and $20 \mathrm{mU} / \mathrm{ml})$ or thromboxane $\mathrm{A}_{2}$ analogue $\mathrm{U}-46619(0.1,0.5$ and $1 \mu \mathrm{M}$ ). As illustrated in Fig. $2 \mathrm{C}$, plateletaggregation following stimulation with the indicated agonist concentrations was significantly affected following threshold concentrations of CRP $(0.25 \mu \mathrm{g} / \mathrm{ml})$, thrombin $(1 \mathrm{mU} / \mathrm{ml})$ or thromboxane $A_{2}$ analogue $U-46619(0.1 \mu \mathrm{M})$. The defect in platelet aggregation was overcome by increasing concentrations of CRP and thrombin whereas thromboxane-induced aggregation was significantly decreased following increasing concentrations of thromboxane $A_{2}$ analogue $U-46619(0.5 \mu \mathrm{M})$ in the presence of p38 MAPK inhibitor Skepinone-L $(1 \mu \mathrm{M})$.

Skepinone-L did not affect stimulation-dependent increase of cytosolic $\mathrm{Ca}^{2+}$ concentration $\left(\left[\mathrm{Ca}^{2+}\right]_{i}\right)$ in platelets.

Sinceplateletsareactivatedbyanincrease of cytosolic $\mathrm{Ca}^{2+}$ concentration $\left(\left[\mathrm{Ca}^{2+}\right]_{\mathrm{i}}\right)$ weexamined the impact of p38 MAPK on platelet cytosolic $\mathrm{Ca}^{2+}$ activity $\left[\mathrm{Ca}^{2+}\right]_{i}$ by using p38 MAPK inhibitor Skepinone-L.Asshown in Fig. 3, a series of spectrofluorimetric calciummeasurements priortoand following CRP $(0.5 \mu \mathrm{g} / \mathrm{ml}, \mathrm{A})$, thrombin $(5 \mathrm{mU} / \mathrm{ml}, \mathrm{B})$ or thromboxane $\mathrm{A}_{2}$ analogue $\mathrm{U}-46619(0.5$ $\mu \mathrm{M}, \mathrm{C})$ stimulation revealed that activation-dependent increase of platelet cytosolic $\mathrm{Ca}^{2+}$ activity $\left[\mathrm{Ca}^{2+}\right]_{\mathrm{i}}$ was similar in the absence and presence of $1 \mu \mathrm{M}$ Skepinone-L.

Inhibition of p38 MAPK by Skepinone-Limpaired activation-dependent of platelet cytosolic phospholipase $A_{2}$ phosphorylation and thromboxane $A_{2}$ synthesis.

In a further series of experiments the effect of Skepinone-L on p38 MAPK-dependent phosphorylation of platelet cytosolic phospholipase $\mathrm{A}_{2}\left(\mathrm{CPLA}_{2}\right)$ and thromboxane $\mathrm{A}_{2}$ synthesis 


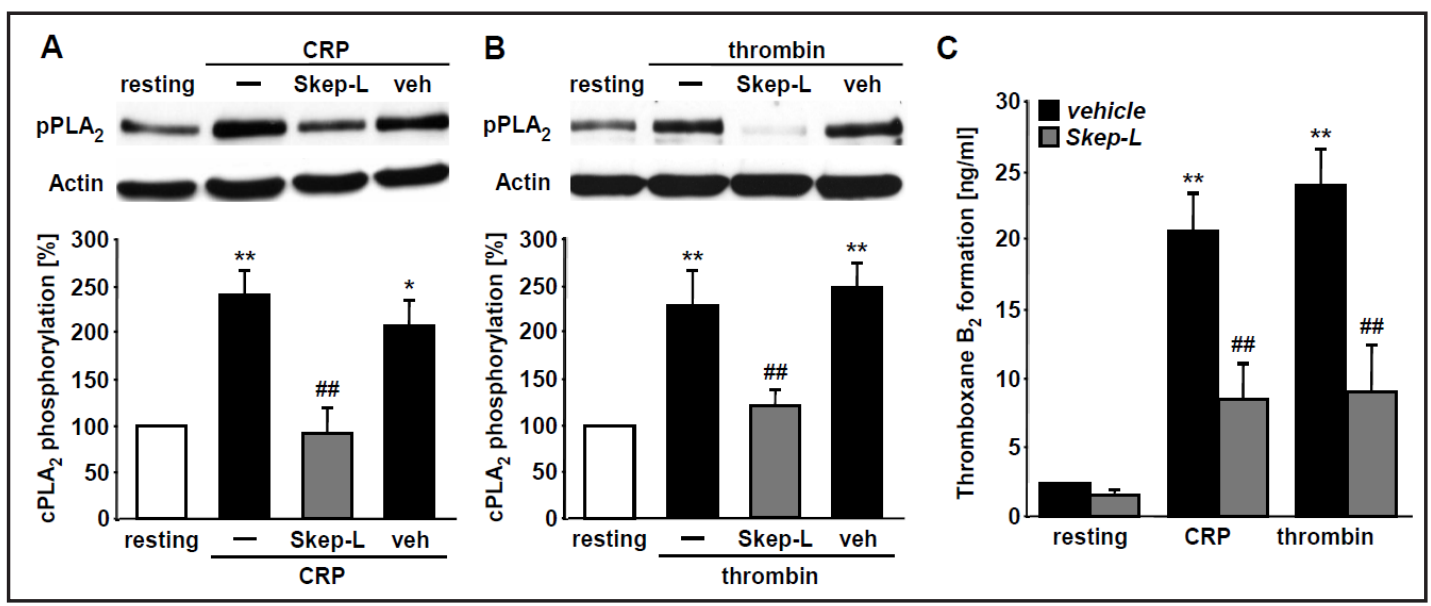

Fig. 4. Skepinone-L impairs phosphorylation/activation of platelet cytosolic phospholipase $A_{2}$ (cPLA $A_{2}$ and platelet thromboxane synthesis. A. Representative Western blot and arithmetic means \pm SEM $(n=6)$ of activation-dependent phosphorylation of platelet cytosolic phospholipase $\mathrm{A}_{2}$ at $\mathrm{Ser}^{505}$ following stimulation with CRP $(1.0 \mu \mathrm{g} / \mathrm{ml}) .{ }^{* *}(\mathrm{p}<0.01)$ or $*(\mathrm{p}<0.05)$ indicate significant difference from value prior to activation, $\# \#(p<0.01)$ indicates significant difference between pretreatment with Skepinone-L or vehicle (DMSO). B. Representative Western blot and arithmetic means \pm SEM $(n=6)$ of activation-dependent phosphorylation of platelet cytosolic phospholipase $\mathrm{A}_{2}$ at $\operatorname{Ser}^{505}$ following stimulation with thrombin $(5 \mathrm{mU} / \mathrm{ml})$. ${ }^{* *}(\mathrm{p}<0.01)$ indicates significant difference from value prior to activation, ${ }^{\# \#}(\mathrm{p}<0.01)$ indicates significant difference between pretreatment with Skepinone-L or vehicle (DMSO). C. Arithmetic means \pm SEM $(n=8)$ of activationdependent platelet thromboxane $\mathrm{B}_{2}$ formation following stimulation with $\mathrm{CRP}(1.0 \mu \mathrm{g} / \mathrm{ml})$ or thrombin $(5$ $\mathrm{mU} / \mathrm{ml}) .{ }^{* *}(\mathrm{p}<0.01)$ indicates significant difference from value prior to activation, ${ }^{\# \#}(\mathrm{p}<0.05)$ indicates significant difference between pretreatment with Skepinone-L or vehicle (DMSO).

upon platelet activation was evaluated. Platelet activation with CRP $(1 \mu \mathrm{g} / \mathrm{ml}$, Fig. $4 \mathrm{~A})$ or thrombin ( $5 \mathrm{mU} / \mathrm{ml}$, Fig. 4 B) was followed by a significant increase of PLA 2 phosphorylation (Ser ${ }^{505}$ ) as well as a significant stimulation of thromboxane formation (Fig. 4 C). Activationdependent $\mathrm{cPLA}_{2}$ phosphorylation at $\mathrm{Ser}^{505}$ and thromboxane synthesis were signficantly blunted in the presence of Skepinone-L (1 $\mu \mathrm{M}$, grey bars).

\section{Skepinone-L inhibited thrombus formation at low and high shear rates}

To elucidate the relevance of Skepinone-L in pathologic thrombus formation, we examined thrombus formation to collagen-coated surfaces under low shear $\left(500^{-s}\right)$ and high shear $\left(1700^{-s}\right)$ conditions. As illustrated in Fig. 5 A, collagen-triggered platelet adhesion and thrombus formation under high arterial shear rates of $1700 \mathrm{~s}^{-1}$ was signficantly impaired after treatment with Skepinone-L $(1 \mu \mathrm{M})$. Under low shear rates of $500^{-s}$ untreated platelets formed massive and dense thrombi after 5 minutes perfusion, whereas Skepinone-L-treated platelets formed only smaller single thrombi with a significantly reduced thrombus surface coverage (Fig. 5 B).

\section{Discussion}

Platelet adhesion and activation are critically important for the development of acute thrombotic occlusion at regions of atherosclerotic plaque rupture, the major pathophysiological mechanism underlying ischemic diseases, such as myocardial infarction or stroke [4, 30, 31]. Several intracellular signaling pathways are involved in platelet activation upon stimulation by contact to subendothelial collagen, thrombin, thromboxane $\mathrm{A}_{2}$ and ADP released by activated platelets. Recent studies have provided evidence that p38 MAPK dependent signaling could be critically involved in haemostasis and thrombosis [6-9]. However, lack of high potency and 


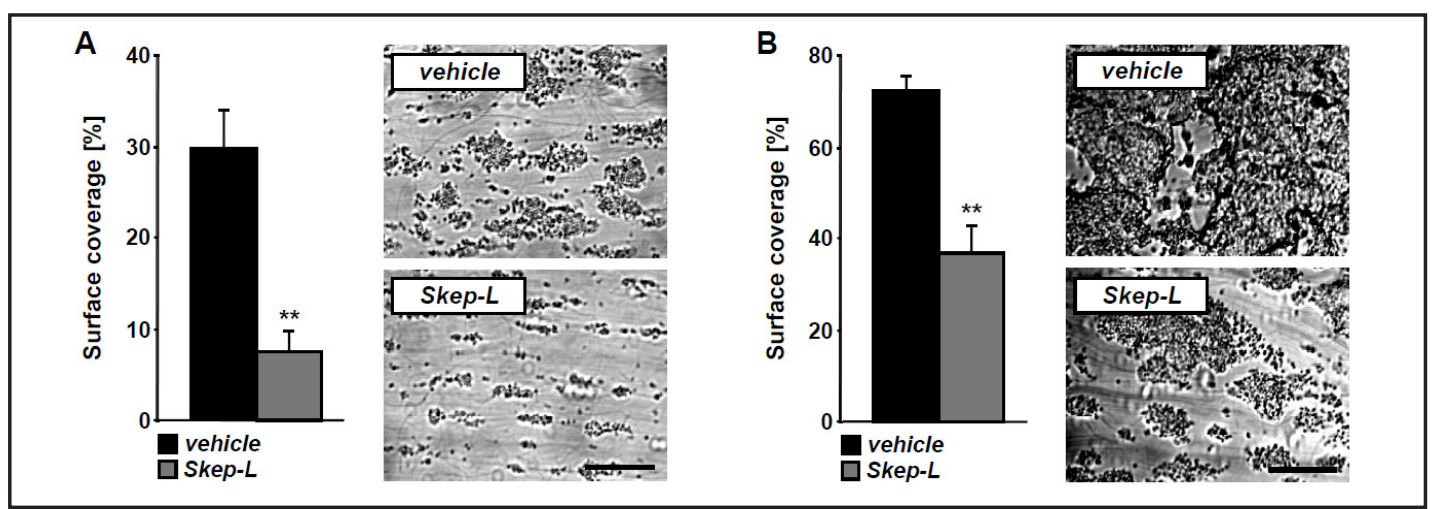

Fig. 5. Activation-dependent in vitro thrombus formation in absence and presence of Skepinone-L. A. Original phase contrast images (left) and arithmetic means \pm SEM $(n=6$, right $)$ of surface coveraging thrombi formed by adherent platelets following perfusion of whole blood over a collagen-coated surface for 5 minutes at high arterial shear rates $\left(1700 \mathrm{~s}^{-1}\right)$ in absence (black bar) and presence (grey bar) of Skepinone$\mathrm{L}(1 \mu \mathrm{M})$. Scale bar equals $50 \mu \mathrm{m} .{ }^{* *}(\mathrm{p}<0.01)$ indicates significant difference between pretreatment with Skepinone-L or vehicle (DMSO). B. Original phase contrast images (left) and arithmetic means \pm SEM $(n=6$, right) of surface coveraging thrombi formed by adherent platelets following perfusion of whole blood over a collagen-coated surface for 5 minutes at low arterial shear rates $\left(500 \mathrm{~s}^{-1}\right)$ in absence (black bar) and presence (grey bar) of Skepinone-L $(1 \mu \mathrm{M})$. Scale bar equals $50 \mu \mathrm{m} .{ }^{* *}(\mathrm{p}<0.01)$ indicates significant difference between pretreatment with Skepinone-L or vehicle (DMSO).

selectivity inhibitors in vitro and especially in vivo has hampered investigation of p38 MAPK signaling pathways in platelet activation and pathological thrombus formation. The novel dibenzosuberone-type p38 MAPK inhibitor Skepinone-L shows outstanding selectivity and high in vivo potency [25].

The observations of the present study using Skepinone-L reveal a decisive role of p38 MAPK-dependent signaling in platelet secretion, aggregation as well as adhesion and thrombus formation under different shear rates. Moreover, p38 MAPK-dependent platelet cytosolic phospholipase $\mathrm{A}_{2}\left(\mathrm{CPLA}_{2}\right.$ ) activation (by phosphorylation at Ser ${ }^{505}$ ) as well as thromboxane synthesis were found to be abrogated in the presence of Skepinone-L, whereas our studies with Skepinone-L indicate that p38 MAPK signaling is not involved in activation-dependent increases of platelet cytosolic $\mathrm{Ca}^{2+}$ activity.

Skepinone-L significantly decreased phosphorylation of Hsp27 in platelets after stimulation with different agonists (CRP, thrombin and U-46619). p38 MAPK can influence platelet degranulation and shape change since Hsp27 acts as a potent modulator of actin cytoskeleton in platelets $[32,33]$. Indeed, platelet adhesion and spreading on collagen has already been shown to be critically regulated via p38-dependent signaling [18].

Furthermore activation-dependent release of platelet dense granules (ATP) was significantly diminished after pretreatment with Skepinone-L, an effect which was overcome by increasing concentrations of CRP and thrombin (Fig. $2 \mathrm{~A}$ and B). In contrast, degranulation following activation with thromboxane $\mathrm{A}_{2}$ analogue $\mathrm{U}-46619$ was still significantly impaired by Skepinone-L even in submaximal agonist concentrations (Fig. $2 \mathrm{~A}$ and B).

According to the present observations, Skepinone-L does not appreciably alter the stimulation-dependent increase of $\left[\mathrm{Ca}^{2+}\right]_{\mathrm{i}}$, following addition of threshold CRP, thrombin or TXA ${ }_{2}$ concentrations indicating that activation-dependent $\mathrm{Ca}^{2+}$ influx in platelets is not critically dependent on p38 MAPK-activity, a finding comparable to the results found with more unselective p38 MAPK inhibitors [15, 21].

According to our studies with Skepinone-L and in agreement with previous findings $[8,21]$ p38 MAPK-dependent signaling seems to be involved in platelet aggregation induced by threshold concentrations of CRP and thrombin (Fig. 2 C). While Skepinone-L-dependent reduction of platelet aggregation following treatment with threshold concentrations of CRP and thrombin was overcome by increasing agonist concentrations, thromboxane $A_{2}\left(T_{X} A_{2}\right)$ - 
triggered platelet aggregation studies show a substantial defect in the presence of Skepinone-L, even at increasing agonist concentrations of the second wave platelet activator TXA $_{2}$ up to submaximal concentrations of $0.5 \mu \mathrm{M}$ (Fig. $2 \mathrm{C}$ ). These results indicate that high doses of CRP or thrombin induce further intracellular signaling that bypasses p38 MAPK dependent signaling similar to the results found for platelet degranulation. TXA $_{2}$ is known to be required for collagen- and thrombin-induced platelet activation in response to threshold concentrations $[3,34]$. p38 MAPK stimulates TXA 2 synthesis upon exposure to threshold concentrations of thrombin or collagen amplifying the initially low platelet response. Moreover, TXA ${ }_{2}$ induces further activation of p38 MAPK resulting in a feedback mechanism of platelet activation. High concentrations of collagen (CRP) or thrombin do not require the amplifying mechanism of p38driven secondary TXA formation for sufficient platelet aggregation.

In addition to its influence on platelet secretion and aggregation, p38 MAPK has been shown to participate in the triggering of platelet phosphatidylserine exposure [35] and agonist-induced bleb formation [33]. The effect on bleb formation but not on phosphatidylserine exposure involves activation of the protease calpain [33]. According to an earlier study von Willebrand factor (VWF)-dependent platelet phosphatidylserine exposure and microparticle formation was paralleled by p38 MAPK activation and bleb formation, but not phosphatidylserine exposure, was abrogated by pharmacological p38 MAPK inhibition with SB203580 [36]. Thus, the experimental evidence addressing the role of p38 MAPK in cell membrane scrambling and membrane blebbing of platelets is conflicting. Notably, p38 MAPK is involved in the triggering of cell membrane scrambling and suicidal death of other cell types, such as erythrocytes [37, 38] and diverse nucleated cells [39-48].

Rupture of an atherosclerotic lesion with endothelial denudation exposes circulating platelets to thrombogenic subendothelial collagen and thus recruits platelets to the injured vessel wall [49]. Inhibition of p38 MAPK by Skepinone-L $(1 \mu \mathrm{M})$ may decrease the risk of collagen-triggered thrombus formation under low $\left(500^{-s}\right)$ and high $\left(1700^{-s}\right)$ arterial shear stress indicating that p38 MAPK is critically involved in different pathways initiating platelet induced thrombus formation. Thus, inhibition of p38 MAPK may be a therapeutic option in the prevention of thrombotic complications. Former in vivo studies in p38 MAPK heterozygous mice already provided first evidence that p38 MAPK seems to be involved in thrombus formation since $\mathrm{Fe}_{3} \mathrm{Cl}$-induced vascular injury of carotid artery results in delayed occlusion time whereas bleeding time of those mice was unaffected [23].

In conclusion, the present observations reveal that the highly potent and selective p38 MAP kinase inhibitor Skepinone-L blunts platelet secretion, aggregation and thrombus formation. Thus, Skepinone-L may prove useful in the treatment of thrombosis. Furthermore this study reports for the first time that selective and potent inhibiton of p38 MAPK by Skepinone-L can reduce thrombus formation under different shear rates. Further studies are now necessary to examine the in vivo potency of Skepinone-L in the protection against arterial thrombosis in vivo. At this stage Skepinone-L could be considered a promising drug in future antiplatelet therapy.

\section{Acknowledgements}

This work was supported by the Tuebingen Platelet Investigative Consortium [TuePIC], the Deutsche Forschungsgemeinschaft - Klinische Forschergruppe [DFG-KFO 274] 'PlateletsMolecular Mechanisms and Translational Implications', Open Access Publishing Fund of Tuebingen University and a Fortüne Resarch Grant to O.B. (2133-B).

\section{References}

Gawaz M, Langer H, May AE: Platelets in inflammation and atherogenesis. J Clin Invest 2005;115:3378-3384. Ruggeri ZM: Platelets in atherothrombosis. Nat Med 2002;8:1227-1234.

Cho MJ, Liu J, Pestina TI, Steward SA, Thomas DW, Coffman TM, Wang D, Jackson CW, Gartner TK: The roles of alpha IIb beta 3-mediated outside-in signal transduction, thromboxane A2, and adenosine diphosphate in collagen-induced platelet aggregation. Blood 2003;101:2646-2651. 
4 Borst O, Schmidt EM, Munzer P, Schonberger T, Towhid ST, Elvers M, Leibrock C, Schmid E, Eylenstein A, Kuhl D, May AE, Gawaz M, Lang F: The serum- and glucocorticoid-inducible kinase 1 (SGK1) influences platelet calcium signaling and function by regulation of Orai1 expression in megakaryocytes. Blood 2012;119:251-261.

5 Canobbio I, Reineri S, Sinigaglia F, Balduini C, Torti M: A role for p38 MAP kinase in platelet activation by von Willebrand factor. Thromb Haemost 2004;91:102-110.

6 Kramer RM, Roberts EF, Strifler BA, Johnstone EM: Thrombin induces activation of p38 MAP kinase in human platelets. J Biol Chem 1995;270:27395-27398.

7 Kramer RM, Roberts EF, Um SL, Borsch-Haubold AG, Watson SP, Fisher MJ, Jakubowski JA: p38 mitogenactivated protein kinase phosphorylates cytosolic phospholipase A2 (CPLA2) in thrombin-stimulated platelets. Evidence that proline-directed phosphorylation is not required for mobilization of arachidonic acid by cPLA2. J Biol Chem 1996;271:27723-27729.

-8 Saklatvala J, Rawlinson L, Waller RJ, Sarsfield S, Lee JC, Morton LF, Barnes MJ, Farndale RW: Role for p38 mitogen-activated protein kinase in platelet aggregation caused by collagen or a thromboxane analogue. J Biol Chem 1996;271:6586-6589.

-9 Borsch-Haubold AG, Kramer RM, Watson SP: Phosphorylation and activation of cytosolic phospholipase A2 by 38-kDa mitogen-activated protein kinase in collagen-stimulated human platelets. Eur J Biochem 1997;245:751759.

10 Abdulrehman AY, Jackson EC, McNicol A: Platelet activation by Streptococcus sanguinis is accompanied by MAP kinase phosphorylation. Platelets 2013;24:6-14.

11 Chang MC, Wang TM, Yeung SY, Jeng PY, Liao CH, Lin TY, Lin CC, Lin BR, Jeng JH: Antiplatelet effect by p-cresol, a uremic and environmental toxicant, is related to inhibition of reactive oxygen species, ERK/p38 signaling and thromboxane A2 production. Atherosclerosis 2011;219:559-565.

12 Etulain J, Lapponi MJ, Patrucchi SJ, Romaniuk MA, Benzadon R, Klement GL, Negrotto S, Schattner M: Hyperthermia inhibits platelet hemostatic functions and selectively regulates the release of alpha-granule proteins. J Thromb Haemost 2011;9:1562-1571.

-13 Lalor DJ, Truong B, Henness S, Blake AE, Ge Q Ammit AJ, Armour CL, Hughes JM: Mechanisms of serum potentiation of GM-CSF production by human airway smooth muscle cells. Am J Physiol Lung Cell Mol Physiol 2004;287:L1007-L1016.

14 Lee YM, Chen WF, Chou DS, Jayakumar T, Hou SY, Lee JJ, Hsiao G, Sheu JR: Cyclic nucleotides and mitogenactivated protein kinases: regulation of simvastatin in platelet activation. J Biomed Sci 2010;17:45.

15 Mazharian A, Roger S, Berrou E, Adam F, Kauskot A, Nurden P, Jandrot-Perrus M, Bryckaert M: Proteaseactivating receptor-4 induces full platelet spreading on a fibrinogen matrix: involvement of ERK2 and p38 and $\mathrm{Ca}^{2+}$ mobilization. J Biol Chem 2007;282:5478-5487.

-16 Schwarz UR, Kobsar AL, Koksch M, Walter U, Eigenthaler M: Inhibition of agonist-induced p42 and p38 mitogen-activated protein kinase phosphorylation and CD40 ligand/P-selectin expression by cyclic nucleotideregulated pathways in human platelets. Biochem Pharmacol 2000;60:1399-1407.

17 Zhu Y, O'Neill S, Saklatvala J, Tassi L, Mendelsohn ME: Phosphorylated HSP27 associates with the activationdependent cytoskeleton in human platelets. Blood 1994;84:3715-3723.

18 Mazharian A, Roger S, Maurice P, Berrou E, Popoff MR, Hoylaerts MF, Fauvel-Lafeve F, Bonnefoy A, Bryckaert M: Differential Involvement of ERK2 and p38 in platelet adhesion to collagen. J Biol Chem 2005;280:26002-26010.

19 Adam F, Kauskot A, Rosa JP, Bryckaert M: Mitogen-activated protein kinases in hemostasis and thrombosis. J Thromb Haemost 2008;6:2007-2016.

-20 Borsch-Haubold AG, Bartoli F, Asselin J, Dudler T, Kramer RM, Apitz-Castro R, Watson SP, Gelb MH: Identification of the phosphorylation sites of cytosolic phospholipase A2 in agonist-stimulated human platelets and HeLa cells. J Biol Chem 1998;273:4449-4458.

21 Kuliopulos A, Mohanlal R, Covic L: Effect of selective inhibition of the p38 MAP kinase pathway on platelet aggregation. Thromb Haemost 2004;92:1387-1393.

22 Yacoub D, Theoret JF, Villeneuve L, Abou-Saleh H, Mourad W, Allen BG, Merhi Y: Essential role of protein kinase $\mathrm{C}$ delta in platelet signaling, alpha IIb beta 3 activation, and thromboxane A2 release. J Biol Chem 2006;281:30024-30035.

23 Sakurai K, Matsuo Y, Sudo T, Takuwa Y, Kimura S, Kasuya Y: Role of p38 mitogen-activated protein kinase in thrombus formation. J Recept Signal Transduct Res 2004;24:283-296.

24 Goldstein DM, Gabriel T: Pathway to the clinic: inhibition of P38 MAP kinase. A review of ten chemotypes selected for development. Curr Top Med Chem 2005;5:1017-1029.

25 Koeberle SC, Romir J, Fischer S, Koeberle A, Schattel V, Albrecht W, Grutter C, Werz O, Rauh D, Stehle T, Laufer SA: Skepinone-L is a selective p38 mitogen-activated protein kinase inhibitor. Nat Chem Biol 2012;8:141-143.

-26 Karaman MW, Herrgard S, Treiber DK, Gallant P, Atteridge CE, Campbell BT, Chan KW, Ciceri P, Davis MI, Edeen PT, Faraoni R, Floyd M, Hunt JP, Lockhart DJ, Milanov ZV, Morrison MJ, Pallares G, Patel HK, Pritchard S, Wodicka LM, Zarrinkar PP: A quantitative analysis of kinase inhibitor selectivity. Nat Biotechnol 2008;26:127-132. 
27 Knapp S, Arruda P, Blagg J, Burley S, Drewry DH, Edwards A, Fabbro D, Gillespie P, Gray NS, Kuster B, Lackey KE, Mazzafera P, Tomkinson NC, Willson TM, Workman P, Zuercher WJ: A public-private partnership to unlock the untargeted kinome. Nat Chem Biol 2013;9:3-6.

28 Borst O, Munzer P, Gatidis S, Schmidt EM, Schonberger T, Schmid E, Towhid ST, Stellos K, Seizer P, May AE, Lang F, Gawaz M: The inflammatory chemokine CXC motif ligand 16 triggers platelet activation and adhesion via CXC motif receptor 6-dependent phosphatidylinositide 3-kinase/akt signaling. Circ Res 2012;111:1297-1307.

29 Wu CC, Hwang TL, Liao CH, Kuo SC, Lee FY, Teng CM: The role of PAR4 in thrombin-induced thromboxane production in human platelets. Thromb Haemost 2003;90:299-308.

-30 Bigalke B, Stellos K, Stakos D, Joos T, Potz O, Geisler T, Bischofs C, Kremmer E, Kramer BF, Seizer P, May AE, Lindemann S, Gawaz M: Influence of platelet count on the expression of platelet collagen receptor glycoprotein VI (GPVI) in patients with acute coronary syndrome. Thromb Haemost 2009;101:911-915.

-31 Fateh-Moghadam S, Htun P, Tomandl B, Sander D, Stellos K, Geisler T, Langer H, Walton K, Handschu R, Garlichs C, Daniel WG, Gawaz M: Hyperresponsiveness of platelets in ischemic stroke. Thromb Haemost 2007;97:974978.

-32 Pichon S, Bryckaert M, Berrou E: Control of actin dynamics by p38 MAP kinase - Hsp27 distribution in the lamellipodium of smooth muscle cells. J Cell Sci 2004;117:2569-2577.

-33 Siljander P, Farndale RW, Feijge MA, Comfurius P, Kos S, Bevers EM, Heemskerk JW: Platelet adhesion enhances the glycoprotein VI-dependent procoagulant response: Involvement of p38 MAP kinase and calpain. Arterioscler Thromb Vasc Biol 2001;21:618-627.

-34 Begonja AJ, Geiger J, Rukoyatkina N, Rauchfuss S, Gambaryan S, Walter U: Thrombin stimulation of p38 MAP kinase in human platelets is mediated by ADP and thromboxane A2 and inhibited by cGMP/cGMP-dependent protein kinase. Blood 2007;109:616-618.

-35 Canault M, Duerschmied D, Brill A, Stefanini L, Schatzberg D, Cifuni SM, Bergmeier W, Wagner DD: p38 mitogenactivated protein kinase activation during platelet storage: consequences for platelet recovery and hemostatic function in vivo. Blood 2010;115:1835-1842.

-36 Song S, Freedman J, Mody M, Lazarus AH: p38 MAPK is activated but not necessary in porcine von Willebrand factor-dependent platelet activation. Br J Haematol 1999;107:532-538.

37 Gatidis S, Zelenak C, Fajol A, Lang E, Jilani K, Michael D, Qadri SM, Lang F: p38 MAPK activation and function following osmotic shock of erythrocytes. Cell Physiol Biochem 2011;28:1279-1286.

-38 Shaik N, Lupescu A, Lang F: Sunitinib-sensitive suicidal erythrocyte death. Cell Physiol Biochem 2012;30:512522.

39 Backorova M, Jendzelovsky R, Kello M, Backor M, Mikes J, Fedorocko P: Lichen secondary metabolites are responsible for induction of apoptosis in HT-29 and A2780 human cancer cell lines. Toxicol In Vitro 2012;26:462-468.

40 Chun J, Joo EJ, Kang M, Kim YS: Platycodin D induces anoikis and caspase-mediated apoptosis via p38 MAPK in AGS human gastric cancer cells. J Cell Biochem 2013;114:456-470.

41 Guo C, Hou GQ, Li XD, Xia X, Liu DX, Huang DY, Du SX: Quercetin triggers apoptosis of lipopolysaccharide (LPS)induced osteoclasts and inhibits bone resorption in RAW264.7 cells. Cell Physiol Biochem 2012;30:123-136.

-42 Hour MJ, Lee KT, Wu YC, Wu CY, You BJ, Chen TL, Lee HZ: A novel antitubulin agent, DPQZ, induces cell apoptosis in human oral cancer cells through Ras/Raf inhibition and MAP kinases activation. Arch Toxicol 2013;87:835846.

43 Kamalden TA, Ji D, Osborne NN: Rotenone-induced death of RGC-5 cells is caspase independent, involves the JNK and p38 pathways and is attenuated by specific green tea flavonoids. Neurochem Res 2012;37:1091-1101.

44 Liu Z, Su YJ, Gu PQ Ji ZY, Wang XG, Gao LJ: The role of the globular heads of C1q receptor (gC1qR) gene in regulating apoptosis of human cervical squamous cell carcinoma. Cell Physiol Biochem 2012;30:1181-1190.

45 Mallick S, Pal BC, Vedasiromoni JR, Kumar D, Saha KD: Corchorusin-D directed apoptosis of K562 cells occurs through activation of mitochondrial and death receptor pathways and suppression of AKT/PKB pathway. Cell Physiol Biochem 2012;30:915-926.

46 Nguyen KC, Willmore WG, Tayabali AF: Cadmium telluride quantum dots cause oxidative stress leading to extrinsic and intrinsic apoptosis in hepatocellular carcinoma HepG2 cells. Toxicology 2013;306:114-123.

-47 Sheng L, Shen Q Huang K, Liu G, Zhao J, Xu W, Liu Y, Li W, Li Y: Upregulation of beta3-adrenergic receptors contributes to atrial structural remodeling in rapid pacing induced atrial fibrillation canines. Cell Physiol Biochem 2012;30:372-381.

48 Zhang Z, Teruya K, Eto H, Shirahata S: Fucoidan extract induces apoptosis in MCF-7 cells via a mechanism involving the ROS-dependent JNK activation and mitochondria-mediated pathways. PLoS One 2011;6:e27441.

49 Dubois C, Panicot-Dubois L, Merrill-Skoloff G, Furie B, Furie BC: Glycoprotein VI-dependent and -independent pathways of thrombus formation in vivo. Blood 2006;107:3902-3906. 